\title{
4. Contracting out as a governance mechanism: the case of national health insurance in India
}

\author{
Maurya Dayashankar and M Ramesh
}

\section{INTRODUCTION}

Contracting out or outsourcing is a part of public sector reform strategy broadly described as privatization. However, instead of shedding a service responsibility or selling off public assets as is normally the case with privatization, the government merely engages a private entity to provide a service of specified quality and price under contract. A key objective of contracting out, not always stated explicitly, is to roll back the state and create more space for the market to allocate society's scarce resources. The strategy seeks to reduce direct provision of services by the state, including internal services, through replacement of public employees and internal procurement processes with contractual arrangements with private firms (Ascher 1987; English and Skellern 2005; Vining, Boardman, and Poschmann 2005; Vincent-Jones 2006; Roehrich, Lewis, and George 2014).

Contracting out is a particular type of governance wherein the government reduces its own role in production by contracting with private producers to provide the service. There are at least three key reasons why governments would contract out a service rather than directly produce and deliver it. First, when the government lacks the resources to accomplish its mission. Second, when the government lacks the productive capacity that relevant private firms possess. Third, when the government lacks the information necessary to produce the service (Coglianese, Zeckhauser, and Parson 2004).

Private firms and markets are the primary focus of contracting out, with no particular role for civil society or networks. Indeed it is arguable that contracting out is not a form of true collaborative governance which is often defined as an arrangement in which all parties have a say in defining both the policy goals and the means (see Donahue and Zeckhauser 2006; Ansell and Gash 2008). On the other hand, if collaborative governance is viewed as a spectrum 
ranging from weak to strong collaboration, then contracting is an example of a weak form with negligible civil society participation. It is, of course, possible to expand the scope of contracting to include engagement with citizens and accommodation of their priorities without compromising the tenets of contracting. The nature of contract and extent of collaboration also depends upon the specific mode of public administration (Dayal, Chapter 14 in this volume). Be that as it may, the primary relationship between the government and the contractor is one of principal and agent, with all its attendant advantages and disadvantages.

As the principal, it is the responsibility of the government to design the contract and ensure it is implemented as intended. The function of designing and implementing contracts is a challenging and delicate task which requires significant capacity on the part of the principal. It particularly requires capacity to generate and analyze information on past and present trends, forecast the future, and use the findings to draw up the contract. In addition to analytical capacity, the government needs capabilities in negotiations and coordination to design contracts and enforce them so that the desired public goals are achieved. Even though contracting out implies reduction of the government's involvement in the provision of goods and services in question, thoughtful negotiation and diligent implementation of contracts requires technical knowledge and the ability to deal with complex quantitative economic and financial issues involved in making the market work (Rayner, McNutt, and Wellstead 2013). Governments without these capabilities end up with poor implementation and sub-optimal outcomes as they are overwhelmed by profit-driven contractors. The Achilles Heel of this mode of service delivery is therefore the lack of policy-analytical capacity which would result in contracts that cannot be enforced or not generate desired outcomes even if enforced.

Regardless of the preconditions necessary for contracting out to work effectively, it is employed extensively around the world. The World Trade Organization estimates that public procurement comprises around 10-15 percent of the GDP globally, including low-income countries. However, most of these transactions are related to simple, well-defined products for which supply contracts are unproblematic. This chapter focuses on the transactions that are of 'quid pro quo' nature - where there is a long-term relation or a long time gap between purchase and delivery-and therefore the nature of the contract itself is an essential element of the transaction (Hart and Holmstrom 1987: 71). The use of contracts as a form to organize economic activity is prevalent in the delivery of a wide range of public services due to widespread belief in the efficiency of private production (Loevinsohn and Harding 2005).

Private production of public services proliferated with the spread of New Public Management ideas and its call for allowing more space for the private sector and market competition (Osborne and Gaebler 1992). Use of contracts 
as a means to organize economic activity experienced tremendous growth during the early years of the privatization movement (Savas 2000) and was an integral part of the New Public Management reforms (Hood 1991). However, the enthusiasm for contracting out public services petered out gradually. In the US, for instance, the level of the contracting out has remained stagnant over the last three decades and in fact there is trend towards 'contracting in' (Denhardt and Denhardt 2015).

To succeed, contracting required a set of conducive conditions without which they led to sub-optimal or even undesirable results (Warner 2008; Rho 2013). Recent systematic reviews (Bel, Fageda, and Warner 2010; Petersen, Hjelmar, and Vrangbæk 2018) have found low and decreasing cost savings from contracts, even without taking transaction costs and quality issues into account. Highest cost savings of around 4-5 percent are observed in technical services while it is almost zero in social services (Bel, Fageda, and Warner 2010). In spite of decades of the research, studies still suffer from methodological issues and do not specifically link cost with quality or take transaction costs into account (Bel, Fageda, and Warner 2010; Petersen, Hjelmar, and Vrangbæk 2018). Petersen, Hjelmar, and Vrangbæk (2018) argue that contracting may work in some instances in the public sector but is frequently unsuitable. Yet, contracting remains the most common alternative to public service delivery.

The core question addressed in this chapter is: What are the conditions for effective contracting? We define effective contracting as a transaction that leads to outcomes that leave both parties better off by engaging in contracting than self-production. We review the existing literature on contracting to identify the factors that influence its effectiveness. We argue that one of the perennial challenges in contracting is how to link cost with quality such that parties in the contract have both incentive to deliver best possible quality at the lowest possible cost. However these two tasks are fundamentally at conflict (Hart, Shleifer, and Vishny 1997) and contracts do not envision various states that vary in quality and cost.

We demonstrate this through a case of National Health Insurance in India, which is an otherwise well-designed contract but crucially fails to link cost to quality and thus results in a number of sub-optimal behaviors of parties. Furthermore, we find that most of the discussion so far has been on incompleteness of the contract due to asset specificity, uncertainty and measurability issues and therefore most suggestions to improve effectiveness of contracting deal with improving contract design, governance mechanisms and capacity issues. Relationship between contract design and governance of the contract has not received the attention it deserves. Our case study demonstrates the importance of aligning contract governance with contract design in improving the effectiveness of the contract. 
In the next section we review the theoretical developments in contracting. This is followed by a section on conditions for effective contracting based on a review of the existing literature. Next, we discuss the challenge of linking cost with quality, including variation in states of quality with variation in production cost. This is followed by analysis of the National Health Insurance in India. The chapter ends with conclusions regarding contract design based on the case study.

\section{THEORETICAL CHALLENGES IN DESIGNING EFFECTIVE CONTRACTS}

Contracts are designed to mitigate conflict of interests, a key obstacle to co-operation. A well designed contract aligns the incentives of different parties to exploit gains from co-operation. However, alignment of incentives is challenging for three reasons (Hart and Moore 1999; Brousseau and Glachant 2002). First, in a complex and unpredictable world it is difficult to forecast and take into account all possible events. This becomes more so in the case of services where there is high uncertainty related to features, outcomes and cost. Uncertainty about the features, quality, outputs and cost of a service requires parties to enter into a transaction without information about cost and performance. Second, even if all events can be predicted, it is difficult for parties to negotiate over all the different possibilities and even to have a common language to describe all states of the world. Third, even if the above two conditions are satisfied, it is difficult to write down all possible contingencies in a contract that can be interpreted and enforced by a third party in the same spirit.

Thus the principles of good contracts must be addressed in contract design in the form of rules regarding task allocation, output specification, payment mechanisms, bilateral procedures for resolving disagreements, contractual safeguards, and supervision/coercion mechanisms (Iossa, Spagnolo, and Vellez 2007; Kim and Brown 2012). They need to be further buttressed by institutional arrangements related to contract enforcement and dispute resolution. These include formal institutions such as courts, the legal profession, and enforcement services (Hadfield 2005) and informal institutions such as social norms, customs, and traditions that either support/reinforce institutional environment or replace/undermine it (Grzymala-Busse 2010).

Contracting in the public sector has additional challenges (Brown and Potoski 2009). First, the decision to contract is generally a result of a political process involving numerous uncertainties. Second, the process of contracting in the public sector is backed by laws that describes how the government needs to engage in contracting and generally an administrative body oversees the contracting process. Third, the government agency that engages in contracting 
would have its own internal policies and practices for procurement and contracting. Fourth, contracting in the public sector is not only about getting the best value for price as it also has to comply with additional requirements like transparency and fairness.

\section{CONDITIONS FOR EFFECTIVE CONTRACTING}

Effective contracts align the contracting parties' incentives in order to exploit gains from co-operation wherein both parties are better off by contracting. For this salutary goal to be achieved, the relationship between the contracting parties needs to be specified along several dimensions (Brown, Potoski, and Van Slyke 2015). First, the product or service being exchanged needs to be specified in order to assure the terms of the exchange. Second, rules of exchange determining apportionment of risk need to be detailed. Third, there needs to be a mechanism to deal with aspects of the relationship that are not formally included in the contract. Fourth, the context in which contracts are entered into and applied has a deep impact on its performance and must be addressed.

\section{Specification of Products and Services}

The contracting process - selection of vendors, contract design and contract management - should be able to provide a level of certainty to the exchange partners about the value each will bring to and receive from the exchange (Brown, Potoski, and Van Slyke 2015). For the buyer, this includes the cost incurred and value derived from the quality and quantity of service received. For the seller, this includes the characteristics of the product or service that is exchanged in the relationship. Certain characteristics of good or service are difficult to write in the contract and, yet, they need to be dealt with in the contract. The difficulty in specifying results form three essential features of many products and services.

The first difficulty relates to experience or post-experience goods in which the buyers and sellers do not know the value of the product's capabilities, features and costs until they take ownership of the good and are therefore unable to describe it before purchase (Weimer and Vining 1992). One possible way is to specify inputs or process, though this may not necessarily lead to desired outputs (Moynihan 2005).

The second problem relates to asset specificity, that is, specialized investments that are unique to the transaction and cannot easily be transferred to another transaction. These specialized investments may be specialized skills/ training in using the product, the production process or plant to make one product that cannot be changed to produce anything else. The specialized 
investments leave the buyer and seller locked into the relationship by raising the costs of changing to another buyer and seller (Klein, Crawford, and Alchian 1978). In such situations, one way out is to divide the contract into multiple contracts such that there is competition between vendors and lower reliance on a single vendor (Brown and Potoski 2005). The other strategy is to clearly define performance measures, measuring and incentivizing them (Brown and Potoski 2005).

The third problem is measurability. The more measurable is the product, the less room there is for one party to take advantage of the other. For some products and services, it is difficult to measure either outcome or activities performed. One can use input measures but quality input doesn't guarantee quality outputs (Moynihan 2005) and effective outputs do not necessarily lead to desired outcomes (McBeath and Meezan 2009). This situation can be addressed by checking the past performance at the bidding stage and by developing a thorough understanding of the production process to get a more clear assessment of the performance if such an assessment doesn't exist (Brown and Potoski 2005).

\section{Exchange Rules}

The specific tasks that buyers and sellers need to take to complete the transaction are exchange rules in a contract. These rules specify the details about the exchange - when, where, amount of compensation and payment method. These rules determine the contract's risks and who bears the risks of transaction under different circumstances. A proper risk allocation requires that the risk is allocated to a party that is responsible or has more control over the risk factor and to the party that is more able to bear it (Martimort and Sand-Zantman 2006). The level of risk allocation should also be such that the parties should be exposed to the risk to the extent they can best manage and minimize that risk (De Bettignies and Ross 2004).

First, the most common exchange rules relates to compensation, that is how much and how the buyer will compensate the seller. Two common forms of compensation are fixed price contracts and cost-reimbursement contracts. The former is commonly used for simpler products whereas the latter is used for complex products that are difficult to describe and produce (Kim and Brown 2017).

The second rule relates to contract length, as it influences competition and efficiency. Uncertainty about the time taken to produce the product affects costs. The nature of the transaction determines the suitability of the contract duration. For example, an investment with higher specificity would require longer contract duration so as to protect the party from hold up (Iossa, Spagnolo, and Vellez 2007). In cases which require flexibility and adaptation 
investment, shorter contract duration is more optimal, allowing switching of providers. The frequent contract renewal and retendering imposes a market discipline on inefficient partners (Calzolari and Spagnolo 2006). On the other hand, long-term contracts can signal credible commitment by each party to deliver value to the other (Amirkhanyan, Kim, and Lambright 2011; Girth et al. 2012).

The third rule relates to bundling of task. The tasks that have positive externality when bundled generate higher social welfare even if the quality is not observable (Iossa, Spagnolo, and Vellez 2007). But when there is no such externality, contracts needs to link cost to quality. The contracts generally keep either cost fixed or quality fixed but rarely both. If the parties have an incentive to reduce cost, they will do so by reducing quality in those dimensions which are not observable to the other party (Hart 2003). Similarly, they can only focus on certain dimensions of quality (gold plating) but not others in order to contain cost and give a false impression of high quality (Brown, Potoski, and Van Slyke 2015). This tradeoff is more prominent in the case of contracting with high information asymmetry regarding production costs and quality. This is worse in situations of open ended complex contracts where ex ante parties are unsure of the actual cost as well as quality of the product/service.

Effective exchange rules require consistency across output specification, payment mechanism and risk allocation (Iossa, Spagnolo, and Vellez 2007). Yet many areas of exchange are often not included in contracts, giving partners considerable room for maneuver and leading to unexpected or sub-optimal results.

\section{Governance Rules}

As all contracts except for the most simple ones are incomplete, the risk of lose-lose outcomes is always present. However, in most cases the values, and formal and informal institutions of the society fill the gaps in contract by incentivizing the performance of desired behavior (Williamson 1985). But these are not sufficient in most cases and would require governance mechanisms to fills the gaps for contracts to be effective (Maurya 2018). The parties generally use a mix of both formal governance mechanisms such as monitoring, authority and penalty as well as informal mechanisms such as reciprocity, trust and relational norms (Wong 2008). The extent to which governance mechanisms are able to fill the gaps in the contract design depends upon the extent of incompleteness of the contract, mix of governance mechanisms (also known as governance design ${ }^{1}$ ) and alignment between governance design and contract gaps (Maurya 2018; Maurya and Ramesh 2018). 


\section{Conducive Contextual Conditions}

A number of contextual factors also affect contract effectiveness. First, the values of internal and external stakeholders shape the contracting context, influence selection of vendor and vendor monitoring (Brown, Potoski, and Van Slyke 2006). For example, in the case of contracting with non-profit agencies, close monitoring may be considered less important given that they are perceived as having similar values as government agencies (Van Slyke 2003). Given the profit motives of the private agencies, on the other hand, contracting is undertaken only when the transaction cost is low and monitoring is used extensively.

Second, institutional arrangements - public laws, ordinances and administrative statutes governing the contracting processes in general and their particular services - influence contact effectiveness (Williamson 2005). The legal requirements may increase the cost of contracting. Institutions also include organizational arrangements that determine resources such as capacity to manage contracts, technical skills in contract drafting and physical capacity. A higher ability to design and manage contracts improves the chances of effective contracting (Brown and Potoski 2005).

Third, the competitiveness of the market also affects contracts' performance. Competition leads to availability of information about cost and service quality across vendors and thus disciplines vendors (Donahue 1989). Solid waste collection, for example, enjoys a highly competitive market (Savas 2005) while high value services such as healthcare and education do not.

\section{NATIONAL HEALTH INSURANCE PROGRAM IN INDIA}

The Government of India launched the National Health Insurance Program (known as Rashtriya Swasthya Bima Yojana or RSBY) in 2008 to address catastrophic health expenditure driving millions to poverty every year. The program's coverage expanded quickly, covering 41 million below poverty line (BPL) families by 2016. The salient features of the program are summarized in Table 4.1 .

As illustrated in the implementation framework in Figure 4.1, provincial governments - through their State Nodal Agency (SNA) - contract with Insurance Companies (IC) to provide health insurance services to families. The contracting is on the basis of service fee per annum (or premium) for each insured family enrolled in the program through a competitive bidding process for each district. The ICs enroll beneficiaries, create a network of hospitals where these enrolled families can seek care, and pay claims to the hospital based on the fixed set of rules. ICs subcontract with other agencies, such as 
Table 4.1

RSBY program features

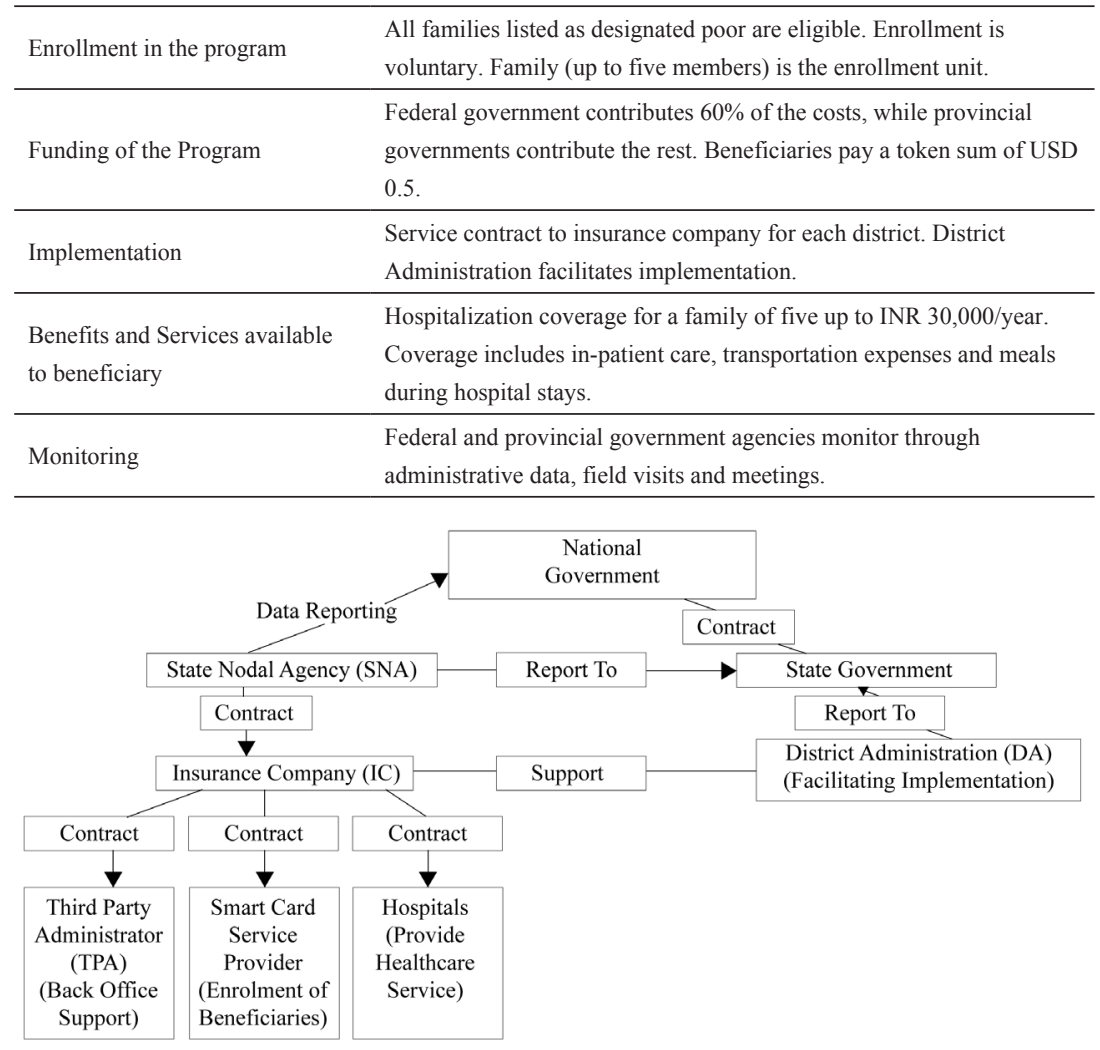

Source: Authors.

\section{Figure 4.1 RSBY implementation framework}

Smart Card Service Providers (SCSP) to enroll beneficiaries, Third Party Administrators (TPA) to create a network of hospitals and manage claims and with hospitals to deliver healthcare services. Thus RSBY design has a nexus of contracts: between SNA and ICs, between ICs and TPAs, and between TPAs and Hospitals. The government has standardized all contracts across the country. This is a critical feature because the similar contract provisions ensure that variations in outcomes are the result of factors other than design. 


\section{Specification of Product and Services in RSBY}

RSBY contracts are detailed and standardized across the country. Asset specificity plays a limited role in RSBY as there is no asset investment. Inputs and processes for all activities as well as, wherever feasible, outputs are listed in detail. Three output measures are considered in assessing the program's performance: enrollment of beneficiary, measured as enrollment ratio; health service utilization, measured as hospitalization ratio; and claims management, measured as share of claims reimbursed within a specific time. These outputs are measured but not used to incentivize performance. For example, there are no targets for any output, and neither any incentive nor disincentive attached to them. Further only the quantitative dimensions of the outputs are measured but not the quality dimensions.

\section{Exchange Rules in RSBY}

RSBY contract design has been revised extensively in order to align the incentives of various parties; however, a number of gaps still remain. Table 4.2 lists the gaps in contract rules and various kinds of perfunctory behaviors they give rise to. One of the most important gaps in the contracting condition is the limited connection between cost and quality during various stages of contracting. This happens as the contract rules focus on containing cost without any reference to quality. For example, all stakeholders are paid on the basis of fixed cost: the insurance company receives a fixed premium per family; the TPA is paid a fixed fee per family; the SCSP receives a fixed fee per card; and the hospitals receive a fixed fee per package. The fixed cost payment method provides strong incentives to control costs but at the risk of compromising quality, especially on dimensions which cannot be monitored or observed (Hart 2003). Further, there is extensive focus on containing cost. The contracts are awarded to the lowest cost bidder, healthcare packages are priced lower than market rates, and contract duration is kept short to contain cost. But quality plays a limited role in the process whether it is contract bidding, payment to agencies, and monitoring of performance. As neither awarding of contract nor revenue of agencies is contingent on quality, agencies have limited incentive to promote quality. This extensive focus on containing cost and lack of attention to quality leads agencies to shed quality especially if it decreases cost. This leads to relative neglect of quality issues in contractor selection and service delivery, resulting in low-cost, low-quality services.

Second, exchange conditions in RSBY induce a volume of services with a limited corresponding impact on health outcomes. This happens as the payments are tied to inputs and process rather than outputs or outcomes, placing the complete risk of outcomes on the contracting agency. The outputs- 
enrollment ratio, hospitalization ratio, claims ratio and percentage of claims reimbursed in the specified time - are measured but not incentivized. As payments are tied to inputs, the contracted entities focus on increasing inputs or process as it increases their revenues but not necessarily outcomes or outputs. For example ICs' remuneration is tied to enrollment therefore they focus on enrollment rather than utilization or health outcomes. Similarly, hospitals' revenues are tied to packages and therefore they tend to provide too many packages, especially high cost packages, which generate higher revenues for them but contribute little to health outcomes for beneficiaries.

Third, exchange rules in RSBY prohibit agencies from taking a long-term perspective. The contract duration is for three years, renewable every year. This short contract duration promotes competition but at the same time reduces incentives to invest in inputs and process that have long-term returns. Because of the short duration, contracting parties (ICs and hospitals) don't focus on preventive care or building claims management capacity to reduce costs as they can easily pass on increases in cost to the government by raising premiums.

Fourth, tasks bundling rules in RSBY result in conflict between individual interest and program objectives. The IC is responsible for paying for the hospitalization of the beneficiary and thus bears the financial risk of healthcare utilization. Therefore the IC is keen to reduce healthcare utilization in order to increase profitability. But at the same time, the IC is also made responsible for increasing healthcare utilization by making beneficiaries aware of the empaneled hospitals and processes for utilizing healthcare services. These two tasks - responsibility for financial risk of healthcare utilization and promoting healthcare utilization - are thus in conflict with each other. As expected, the IC does not promote healthcare utilization, limiting the effectiveness of the program.

\section{Contractual Conditions in RSBY}

One of the critical contextual conditions is alignment of values between parties and its impact on contract selection, contract management and contract performance. In jurisdictions where public organizations (public insurance companies and public hospitals) dominated in the network, conflict between agencies and opportunism was found to be lower. Profit-oriented private hospitals in general have a higher tendency to induce demand, especially among insured patients (Bhat 2005). Higher engagement of private hospitals was found to have a higher incidence of fraudulent behavior (Asher, Vora, and Maurya 2015; Maurya and Ramesh 2018).

The second critical contextual condition is the institutional environment (Maurya 2018). In India, private hospitals deliver around 60 percent of all the inpatient care (National Sample Survey Organization 2015), but are subject to 
limited regulation (Peters and Muraleedharan 2008) which limits the ability of governments to influence the sector. Further, because of corruption and high transaction costs of using formal institutional arrangements, parties in dispute tend to seek extra-legal solutions (Kapur, Mehta, and Vaishnav 2017). In the case of healthcare, limited regulation further limits the ability of governments to influence the sector. RSBY as a result relies on private institutional arrangements to resolve differences. In case of dispute, agencies are expected to use a three-tiered internal grievance redressal mechanism with grievance committees constituted at district, provincial and national levels. These committees are expected to preside over arbitration and recommend decisions but have no legal power and therefore can't impose legal sanctions, except non-renewal of the contract and/or de-barring the agency from bidding in future. In practice, the grievance system faces many challenges in functioning effectively. First, no penalty has been identified if the opportunism is committed by a public functionary and thus the system is biased against the private sector entities. Second, given low literacy levels and high transaction costs in using the system, the beneficiaries of the programs do not formally record their grievances against hospitals or ICs.

The third contextual condition affecting performance is the capability to design and manage contracts. Provincial governments in India generally have limited capacity to draft and manage contracts (Venkat Raman and Björkman 2009). To overcome this, standardized contracts were created and a dedicated agency was appointed at state level to manage contracts with the help of professional staff hired on a contractual basis. However, states differed in terms of staffing at SNA leading to variations in governance capacity. Also the ICs have limited capacity to manage the health insurance functions as they haven't invested in building this capacity and rather relied on unethical approaches to control costs (Bearing Point 2008). The small size of the health insurance business (according to IRDAI 2016, health insurance comprised only 6 percent of the total insurance sector business), lack of standardization in various areas (treatment, records, billing process, etc.) and slim profit margins has prevented investment in capacity building (Maurya, Virani, and Rajasulochana 2017).

Finally, the level of competition in RSBY programs has a significant influence on performance. There are 15 ICs, 24 TPAs, and thousands of hospitals which bid for contracts in RSBY. The ex ante competition has led to a reduction in premium over the years (Ministry of Labour and Employment 2014). However, there is little competition among healthcare providers, especially in rural areas, increasing the risk of supplier-induced demand due to limits on second opinion (Desai 2009). 
Table 4.2 Gaps in contract rules and resulting perfunctory behaviors

\begin{tabular}{ll}
\hline Contract rules & Perfunctory behavior \\
\hline $\begin{array}{l}\text { Competitive contract bidding based only on } \\
\text { cost }\end{array}$ & IC bid aggressively comprising quality \\
Short contract period of three years renewable & Stymies investments by IC in preventive care, \\
every year & management capability, etc. \\
Payment based on inputs and process & Tendency to induce volume of service but limited \\
& impact on outcomes \\
& a. IC has incentive to encourage enrollment but \\
& discourage utilization. \\
& b. SCSP has incentive to enroll but may not enroll all \\
& family members. \\
& c. Hospitals provides multiple packages and \\
& unnecessary services that not necessarily lead to \\
& improved health status. \\
& All stakeholders - IC, TPA, SCSP \& Hospitals- have \\
incentive to reduce cost by decreasing quality of \\
services \\
Incentives to shed quality \\
Limited performance incentives & Shirking behavior \\
\hline
\end{tabular}

\section{Governance Rules in RSBY}

Health insurance contracts are complex and unavoidably incomplete due to limitations to assessing quality, costs, and outcomes. Consequently, program administrators must develop processes and practices that fill, offset or minimize the gaps if the program is to be effective. To address the gaps in program design, a number of implementation mechanisms have been put in place. For example, detailed performance indicators, both quantitative and qualitative, are defined. National-level nodal officers meet every month while state-level nodal officers meet with ICs every six months to review the program's implementation. Field key officer and district administrators are required to monitor implementation through regular field visits. The contract document includes detailed guidelines for processes mentioned in the contract. However, the program administrators are aware of the limits of contract and, hence, engage in informal collaboration and trust-building to supplement the formal arrangements. Agencies are expected to work as a 'team and facilitate and support each other' and are advised to 'sit together and discuss' through internal grievance redressal mechanism in case of dispute (Swarup 2012). 


\section{INTERPLAY OF CONTRACTUAL CONDITIONS AND CONTRACT EFFECTIVENESS}

Interplay among contractual conditions determines incentives to agencies and ultimately their behavior. One of the themes across all perfunctory behaviors is quality shedding behaviors. RSBY's exchange rules focus on costs and make no effort to link cost to quality during various stages of contracting (selection of vendor, contract design, and contract management). This promotes sub-optimal behavior by contracting parties. As the focus is on controlling cost rather than quality, parties compromise on quality in order to control cost. Experience elsewhere suggests that if the focus had been on quality without attention to cost, the parties would have found ways to inflate costs (Brown, Potoski, and Van Slyke 2015). Therefore both cost and quality requires attention and contracts need to links them otherwise parties tend to exploit the tradeoff between them. Further, contracting improves quality of services only along those dimensions which are observable.

Apart from quality shedding and cost inflation, implementing partners had incentives for a number of other perfunctory behaviors, as discussed earlier. However, dynamics during program implementation determined the extent to which these behaviors were exhibited. One of the critical implementation dynamics is the dependence of the IC on DA and the latter's exploitation of this dependence. Under RSBY's current design, the ICs' revenues are based on the number of families enrolled, but they cannot complete the enrollment without the support of DA, which allows the latter to exploit the dependence and engage in opportunistic behavior, including corruption. Anecdotal evidence suggests that DA officials accept bribes from hospitals in return for recommending them for empanelment (Asher, Vora, and Maurya 2015; Maurya 2015), a recommendation the IC cannot turn down due to its dependence on the DA. In rural areas, a number of hospitals came into existence after the launch of the program and were empaneled even though they did not meet the qualification criteria. Once empaneled, such hospitals engaged in fraudulent claims (Maurya 2015). DA is the Chair of the District Grievance Committee that further limits an IC's option to resist pressure from DA.

As discussed earlier, private hospitals are subject to almost no regulation regarding quality or price and are known to induce demand, especially in the case of insured patients (Bhat 2005; Bearing Point 2008). RSBY beneficiaries also do not resist the demand-inducing behavior of hospitals due to absence of co-payment. Under the immunity of DA, hospitals engage in various perfunctory as well as fraudulent behaviors - providing low-quality services, selecting low-cost cases (cream-skimming), accepting informal payments, treating ghost patients, and claiming multiple packages (Press Trust of India 2013). 
Unable to control hospitals, ICs resort to unethical measures to control claims, such as rejecting claims on minor technical grounds, delaying claim payments, paying amounts less than actual claims and preventing claim submissions through various ways. Faced by ICs' opportunistic behaviors, hospitals further inflate claims which in turn promotes another cycle of opportunism and counter-opportunism. However, this was not observed uniformly across all states. In states where public hospitals dominated in RSBY hospital networks, lower levels of fraud were observed, as public hospitals have limited incentives to bribe and induce demand (Maurya and Ramesh 2018). Furthermore, states which were able to keep DA out of the hospital empanelment process and provided complete autonomy to ICs, were able to minimize the opportunistic behavior of DA and contained the cycle of opportunism and counter opportunism (Maurya and Ramesh 2018).

\section{DISCUSSION AND CONCLUSION}

While there are instances when significant benefits may be reaped through contracting out, it is not as easy a governance tool as often suggested by its protagonists. The nature of the contract and how it is implemented has a major impact on how the services are produced and distributed and their impact on outcomes. Particularly, effective contracting requires appropriate alignment of contextual conditions, exchange rules and governance rules such that the contracting parties engage in consummate behavior and avoid perfunctory or predatory behavior.

The primary challenge for contract design is aligning the implementing partners' different motivations and incentives. The challenge is particularly severe in contexts and sectors characterized by information asymmetry, uncertainty and asset specificity. One of the steepest challenges in contracting is to promote incentives for reducing cost while ensuring quality at the same time. Tradeoff between cost and quality needs to be addressed by linking cost and quality during different stages of contracting. If the linkage is missing in even one of the contracting stages, the implementing agencies may exploit the tradeoff to their own advantage. The case of RSBY demonstrates that it is difficult to identify and address all eventualities that the contract will face during implementation.

During implementation, contract design rules and contextual conditions either heighten, dampen or distort various incentives. Contextual conditions such as formal institutions impose high transaction costs in emerging economies such as India, which lead parties to use private arrangements or informal norms. The case of RSBY suggests that private arrangements aimed to fill the institutional void can in fact worsen the situation as they may be biased and designed to suit self-serving sectional interests.

Incomplete performance contracts necessitate governance measures to minimize or address the gaps during implementation. If the deployed governance 
measures match the contract design then the contract is executed as intended and leads to expected outcomes. Misaligned governance mechanisms, on the other hand, not only fail to bridge the gap in contract design but may actually aggravate them. The case of RSBY demonstrates that contract governance could substantially influence contract performance.

Contract design gaps in RSBY provide a number of opportunities for collusion and rent seeking. Contracts governance in RSBY relies predominately on collaboration among agencies to fulfill the contract gaps. Without provision for penalty, disputes are addressed through discussions and negotiations. However, collaboration alone is not effective when there is conflict of interest and dependency relationships between agencies (Vangen and Huxham 2003). The overreliance on collaboration failed to control veto power and dependency relationships, resulting in weak accountability. In states where public agencies exercised authority to control veto power and dependency relations, accountability improved and performance was higher. Therefore collaboration as a contract governance approach adds only marginal value to production. More attention needs to be given to contract governance which has remained at the margin in the extant literature which is focused on contract design and contextual conditions.

In large-scale public programs, contracts are designed at the national level with uniform features; however, jurisdictions vary in the contextual conditions, and capability in contract design and management. These variations give rise to different types and scale of perfunctory and predatory behaviors. Implementing managers can do little to prevent these behaviors as they have limited control on contextual conditions or contract design. But they can control these behaviors substantially through governance of the implementation process. However, the deployment of desired governance mechanisms may not always be feasible as it depends upon their availability as well as capability of agency. The case of RSBY demonstrates that a particular governance mechanism may not be available in a given context due to meta-governance rules and administrative structures leading to variation in governance dynamics and performance.

In order to be effective, contracting requires a number of conditions to be met which points to the need for cautious use, especially in sectors characterized by market failures and measurability challenges. Treating contracting as a panacea to solve capability deficits or governance failures may worsen the situation, as the contracting requires substantial policy analytical as well as governance capacities. If governments find it is difficult to produce a service in-house, they are unlikely to find contracting out an easy solution to their internal limitations.

\section{NOTE}

1. For more details refer to Howlett and Ramesh (2014). 